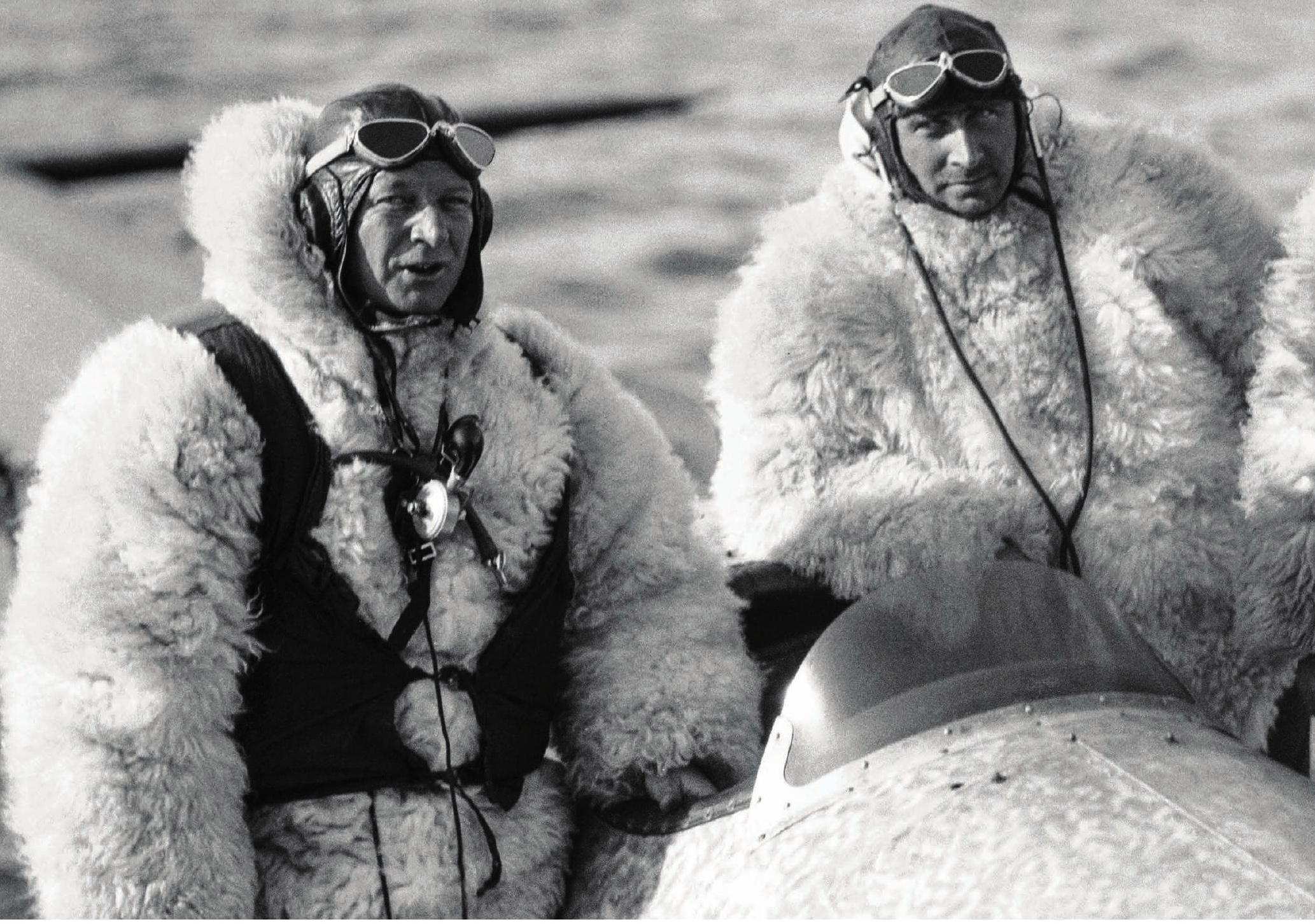

\title{
The ice historians
}

TO TELL WHETHER GREENLAND'S GLACIAL CAP WILL MELT AWAY ANY TIME SOON, RESEARCHERS ARE PORING OVER OLD PHOTOGRAPHS AND DRAWINGS FOR CLUES TO ITS PAST BEHAVIOUR. 
during Danish-US Greenland aerial surveys from the 1940s to the 1970s. Then came pictures from Danish mapping expeditions carried out from 1978 to 1987. Bjørk has now amassed a collection of 180,000 aerial photographs (see 'Flight lines'). But he has paid particular attention to the first images he acquired, from the 1930s, because they chronicle a warm period that shares some similarities with the present. The mapping expeditions, led by the explorer Knud Rasmussen, were partly motivated by a dispute with Norway about which country had sovereignty over Greenland - a legal battle that the international court in The Hague settled in 1933 in favour of Denmark. But the crews were aware of the scientific potential of their work. "The instantaneous record contained in the air and terrestrial photographs of the present state of the glaciers of the entire coast is in itself of great value for future researchers," the Danish captain Carl Gabel-Jørgensen wrote in a 1935 report.

\section{“WITHOUT GPS OR OTHER PRECISION TOOLS THEY STILL MANAGED TO PRODUCE GLACIER DATA OF AMAZING QUALITY.”}

"These men were professionals," says Eric Rignot, a glaciologist at the University of California, Irvine, whose group Bjørk will join in the autumn as a postdoc. "Without GPS or other precision tools they still managed to produce glacier data of amazing quality."

The image collection from the 1930s includes 10,000 overlapping aerial photographs captured with a rotating camera flown in an open hydroplane at 4,000 metres altitude. Bjørk and his colleagues have used these images - alongside more recent aerial images and satellite observations - to produce an 80-year record of how 132 glaciers in southeast Greenland have waxed and waned ${ }^{1}$. They found that the glaciers retreated strongly during both warm periods but many have lost more ice during the record temperatures in recent decades.

Not all glaciers have responded to warming in the same way. It has hit low-elevation glaciers harder than ones higher up, and glaciers that terminate in the sea seem to be more vulnerable to the present rise in temperatures than those that end on land. Researchers are particularly concerned about how quickly these marine glaciers might shrink as they are attacked by the rapidly warming ocean. That may be a key factor in determining how quickly Greenland loses ice.

The signs are not good. Hundreds of outlet glaciers that drain the ice sheet are losing substantially more mass and are thinning more than they are gaining through snow accumulation. Jakobshavn, one of Greenland's largest glaciers, is moving faster than all the others and is the poster child for the fragile ice sheet, which some fear might approach a fatal tipping point as air temperatures continue to rise and the glaciers thin even more ${ }^{2}$.

The findings from the historical studies released so far are a reminder that the current glacier retreat has lasted far longer and is more pronounced than the typical fluctuations over the past century. "It's that kind of long-term perspective that helps us understand that the rapid changes we are seeing now are definitely more than just noise," says Csatho, who has looked at satellite and aerial data to reconstruct how the surface elevation of the Greenland ice sheet changed at nearly 100,000 locations from 1993 to 2012 (ref. 3).

\section{RECOVERED TREASURE}

Bjørk's work at the Arctic Institute in Copenhagen is more sedate than his trips to Greenland, but no less rewarding. The centre's archives hold treasured documents and memorabilia of Denmark's Greenland expeditions, which are part of the Nordic kingdom's cultural DNA. Bjørk gleams with the delight of an art lover as he unrolls maps drawn by Danish explorer Hinrich Rink in 1851 of the mighty Jakobshavn. Carefully opening stitched albums, Bjørk passes by snapshots of Inuit villagers with sealskin boats, and heads for the pages that most interest him - the sketches and images depicting the shapes of glaciers and their thickness.

"Rink and later explorers documented very carefully where they were, and we can trust that what they painted is exactly what they saw," he says. "Their zeal and accuracy is a gift for us."

Bjørk has done much of his work with fellow geographer Kristian Kjedlsen, with whom he shares an office in the Natural History Museum plastered with Greenland maps and Arctic photography. In a second study, they and their colleagues carefully picked out geographical features on old photographs, such as moraines of rock or vegetation lines

\section{FLIGHT LINES}

Anders Bjørk and his colleagues are using historical aerial surveys to assess Greenland's glaciers, including 309 major ones $(\bullet)$ that drain the ice sheet. Blue lines represent flight tracks.
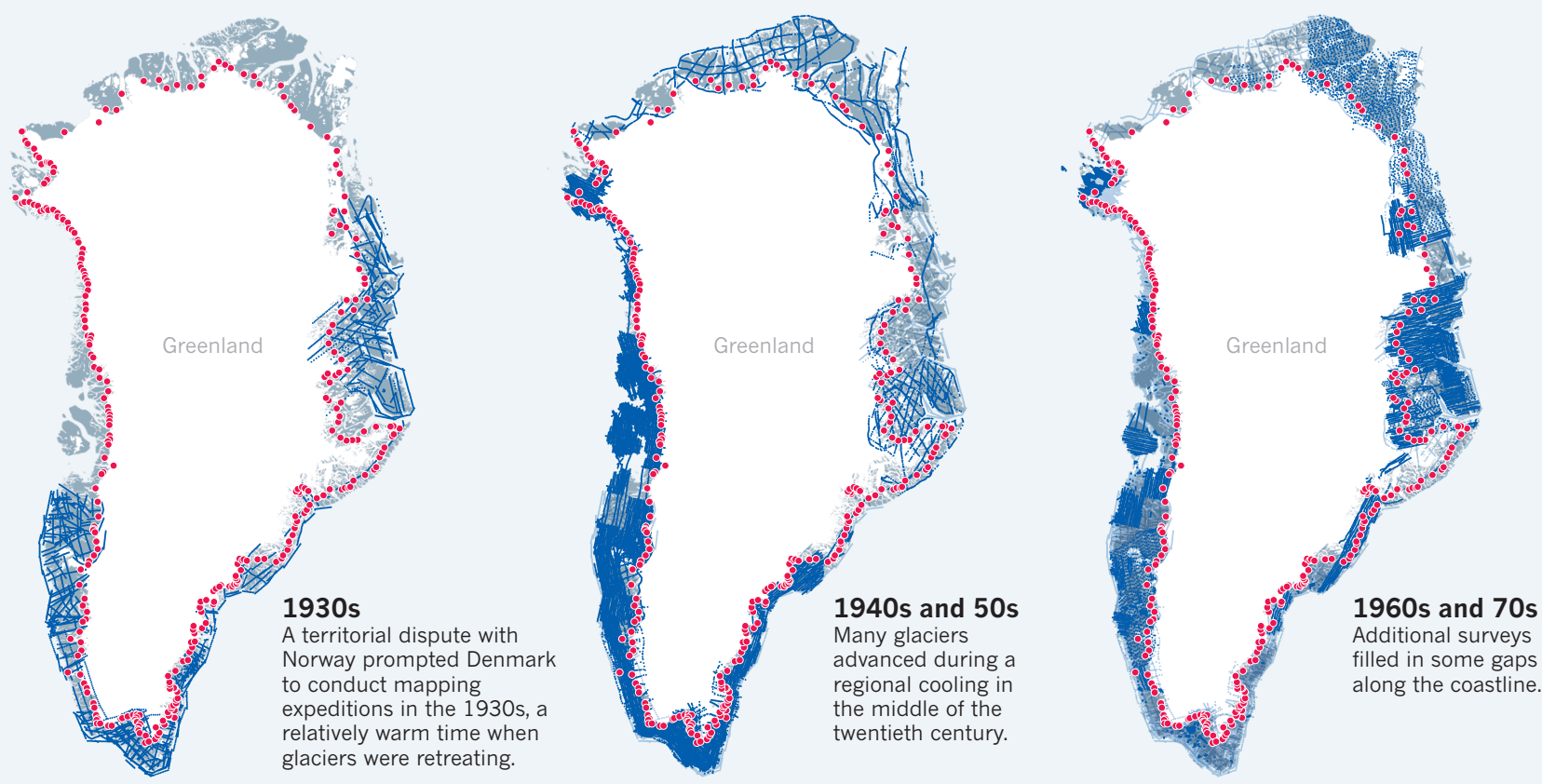


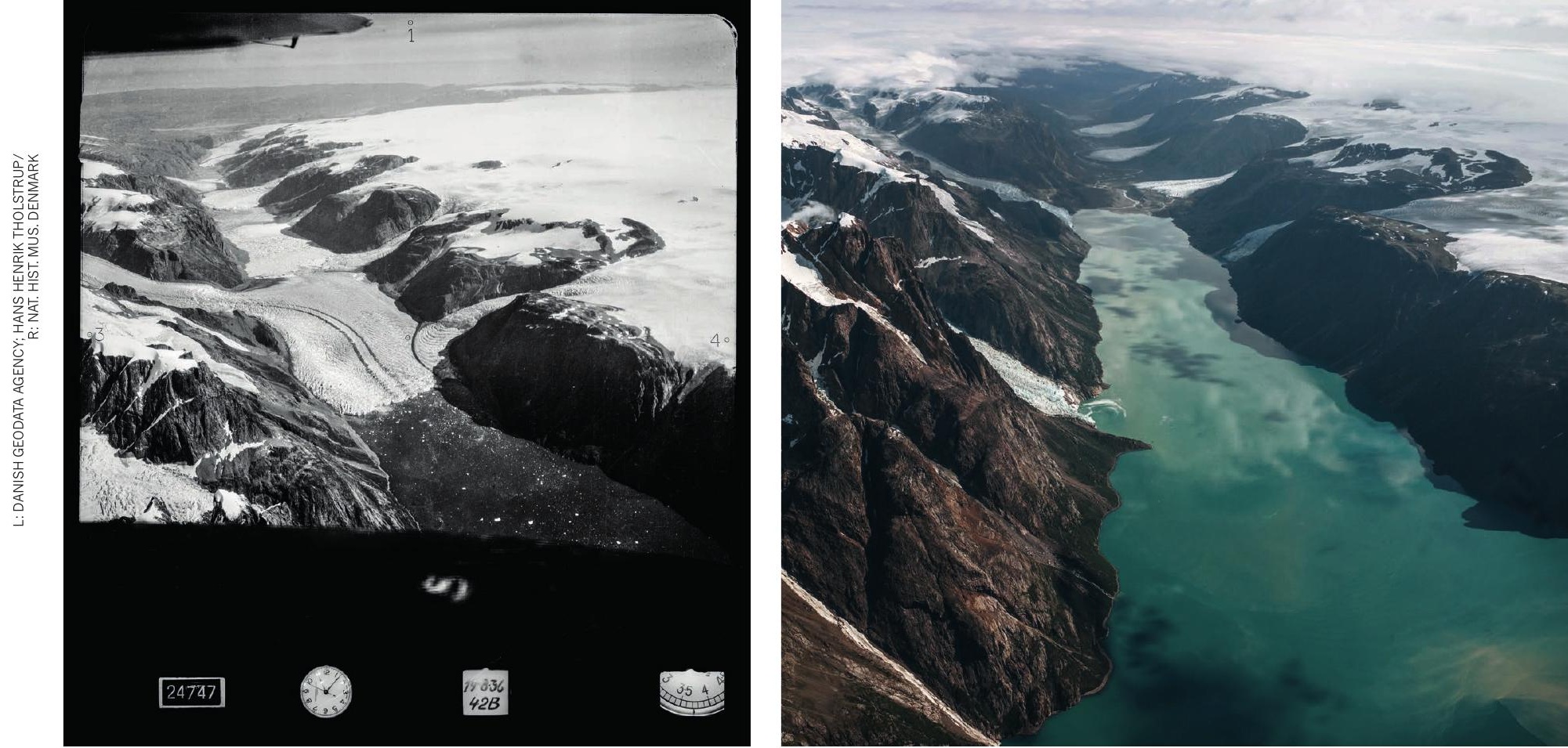

Photographs of Ujaraannaq Valley in southwest Greenland in summer in 1936 (left) and in 2013 show that several glaciers have disappeared.

that mark the greatest extent of the glaciers during the Little Ice Age at the end of the nineteenth century.

They used these data, along with more recent aerial surveys, to determine how the height of the glaciers has shifted, which provides a way to track changes in the ice mass. Their results indicate that the mean annual rate of ice loss between 2003 and 2010 was more than double the average for the twentieth century ${ }^{4}$. Moreover, striking spatial differences seem to confirm that the ice sheet's response to changing climates is governed by the topography of the underlying bedrock and by the geometry of the fjords through which outlet glaciers are flowing towards the sea.

\section{UNRULY ICE}

Greenland's glaciers have been fickle over the past century, advancing in some places and retreating in others. By discovering when those changes happened and what kind of conditions prevailed at the time, Bjørk and his co-workers hope to shed light on the ice sheet's complicated mechanics - a missing piece in attempts to model its waxing and waning accurately.

But nailing the ice sheet's behaviour requires looking at as many individual glaciers as possible. This is just what Bjørk and his group are doing now. Using all available historic records from Greenland, including pictures of glaciers in the least-explored high north, alongside modern satellite imagery, he aims to reconstruct the history of the island's 309 biggest glaciers in unprecedented detail.

The work is in full swing. On most days, two of his students toil away in the basement of the museum in front of computers, clicking on boulders, cliffs and other recognizable features that can be spotted in photographs taken decades apart. These are control points, which allow the researchers to match pictures captured at different altitudes and angles. Most aerial pictures were not taken looking straight down and hence lack a single scale. All of these oblique pictures need to be converted, one by one, to vertical views so that they can be transferred onto a common coordinate system. Without doing this geo-rectification, the researchers could not accurately measure the glaciers' advances and retreats.

Photos are not the only source of information. In the Arctic Institute on a sunny afternoon, Bjørk looks at sketches that the German geologist Alfred Wegener produced during his last expedition, shortly before he died in November 1930 near an ice camp in central Greenland. Other albums hold illustrations of glaciers that scientists made during field trips in a cold spell in the late nineteenth century.

So far, he has discovered about 600 sketches and paintings that might help to tell the story of Greenland's glaciers before aerial photographs first became available. For some glaciers, official aerial pictures don't exist. To fill the gaps, he is also consulting privately held images that geologists have taken over the years. "New information is coming up from all sides," he says.

In 2014, the daughters of two pilots involved in the 1930s surveys offered Bjørk their large collections of photos and even an 8-millimetre film their fathers had taken during the campaigns.

The emerging story is that ice disappeared very fast in the early twentieth century in the warming that followed the end of the Little Ice Age. Then the subsequent cool spell brought widespread glacial advances. The profound switch between shrinking and surging suggests that the glaciers are more sensitive to warmings and coolings than researchers had previously thought, says Bjørk. But why some glaciers advanced forcefully at given periods and temperatures whereas others did not is still a puzzle.

NASA has launched the Oceans Melting Greenland (OMG) project, led by Rignot, to provide glaciologists and ice-sheet modellers with unprecedented base maps of fjord bathymetry and other information needed to determine how glaciers interact with the sea. That is where one of Bjørk's latest discoveries could prove useful. The historic records of sea-surface temperature that he unearthed can be combined with the individual histories of different glaciers to see how those that end in the ocean responded to changing marine conditions. The past behaviour of the ice, Rignot says, "matters a great lot when it comes to projecting its fate".

After all, the ultimate goal of this historical research is to look forward. Along with palaeoclimatic data from hundreds and thousands of years ago, the findings of Bjørk and his colleagues from the recent past promise to increase confidence in the projections of ice-sheet models, says Richard Alley, a glaciologist at Pennsylvania State University in University Park. "We need history as well as modern observations to build and test predictive models."

For Bjørk, the historical research goes well beyond science. It also connects him with the pioneering scientists and explorers he grew up admiring. He is grateful that their legacy is finally being dug out from the crypt. "It's part of Nordic history," he says, "and a real gift to modern science." -

\section{Quirin Schiermeier writes for Nature from Munich, Germany.}

1. Bjørk, A. A. et al. Nature Geosci. 5, 427-432 (2012).

2. Gregory, J. M., Huybrechts, P. \& Raper, S. C. B. Nature 428, 616 (2004).

3. Csatho, B. M. et al. Proc. Natl Acad. Sci. USA 111, 18478-18483 (2014).

4. Kjeldsen, K. K. et al. Nature 528, 396-400 (2015). 